\title{
Effect of trephination technique on the ultrastructure of corneal transplants: guided trephine system $v$ posterior punch technique
}

\author{
W Radner, Ch Skorpik, R Loewe, C Mudrich, G Radner, R Mallinger
}

\begin{abstract}
Aim-Different trephination methods may lead to differences in degree of tissue damage and endothelial cell loss, which both influence the outcome of penetrating keratoplasty. Light, transmission, and scanning electron microscopy were used to compare the ultrastructural appearance of the cut edges and the endothelial cell loss in 26 human corneal donor buttons obtained by trephination with the suction fixated guided trephine system (GTS) and with the free hand posterior punch technique (PPT).

Methods-Human corneas were stored between 5 and 14 days in Optisol. One cornea from each pair was used for each technique. Trephinations $(7.5 \mathrm{~mm})$ were performed either from the anterior direction with the GTS $(n=13)$ or from the posterior direction with the PPT $(n=13)$ using Pharmacia Superblade trephines. Light microscopy, transmission electron, and scanning electron microscopy were performed according to standard procedures. Widening of the cut edges and the extent of endothelial cell loss were measured at three different areas per corneal button and analysed statistically.
\end{abstract}

Results-In contrast with the PPT, the GTS trephine produced considerable fibrillar disorder at the cut edges of the corneal buttons. The distance to which the endothelial cell loss extended from the edges of the cuts was significantly $(\mathbf{p}<0.001)$ lower for the GTS (42.2 (SD 50.8) $\mu \mathrm{m}$ from the edge) than for the PPT $(109.3(68.1) \mu \mathrm{m})$. Stromal widening at the edges (measured as percentage increase in stromal thickness, compared with the thickness of the central cornea) was observed with both techniques. However, the mean stromal widening produced by the GTS was significantly greater than that produced by PPT (106\% (24\%) $v 69 \%$ $(21 \%)$; $\mathrm{p}<0.002)$.

Conclusion-Both trephination techniques produced only minor tissue damage. Nevertheless, there were distinct differences in the fine appearance of the cuts produced by the GTS and the PPT techniques. The extent of the fibrillar dislocation and stromal widening was greater at the edges of the GTS buttons. The GTS technique produced significantly less endothelial cell loss at the cut edges than did the free hand punching technique, PPT.

(Br F Ophthalmol 1999;83:1172-1177)

High and irregular astigmatism is a significant problem after penetrating keratoplasty (PKP). ${ }^{12}$ Despite advances in mechanical trephine design and suture technique, the mean postoperative astigmatism is reported to be between 2.5 and 5.0 dioptres (D) in large keratoplasty series. ${ }^{13-6}$ This postoperative astigmatism is most probably a result of imprecise trephination or differences in size and undercut between the donor button and the recipient cornea. ${ }^{1378}$ In addition, corneal scars after PKP are a source of weakness, and dislocation of the donor button can appear even after adequate healing. ${ }^{9} 10$ Thus, the shape of the cutting edges and the perfect fit of the graft in its recipient bed are important factors in producing a satisfactory outcome in PKP.

Another very important factor in the postoperative period is the maintenance of an adequate quantity of intact endothelial cells which are essential for corneal transparency and nutrition. ${ }^{11}$ Prospective and retrospective studies have shown that during the first 3 years after PKP a central decrease of endothelial cell number occurs at a rate of $21 \%$ per year, then declines to a level of $0.5 \%$ per year ${ }^{12-14}$; the overall cell loss after 10 years averages $73 \% .{ }^{15}$ The greatest degree of endothelial cell loss, however, unquestionably occurs during the PKP itself (real loss), as result of the damage occurring at the edges of the grafts and recipient corneas. ${ }^{16-18}$

Corneal grafts can be obtained by trephination from the epithelial side or from the endothelial side. ${ }^{19}$ Different trephination methods may cause different types and degree of tissue damage and endothelial cell loss, which both influence the outcome of PKPs. ${ }^{2}$ We have now compared the edges of 26 corneal donor buttons obtained either by trephination from the epithelial side with the suction fixated guided trephine system (GTS) or from the endothelial side with the posterior punch technique (PPT) by means of light microscopy (LM), transmission electron microscopy (TEM), and scanning electron microscopy (SEM). In addition, we have developed a method at the microscopic level to quantitate the effects of various trephination techniques on stromal widening and endothelial cell loss. 
Epithelium

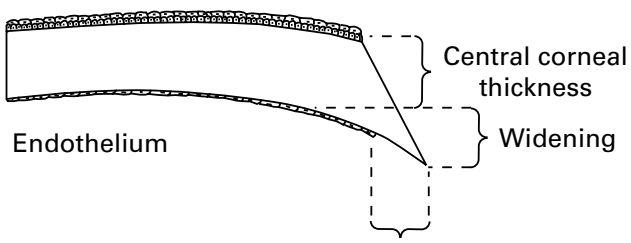

Endothelial cell loss

Figure 1 Graphic representation. Endothelial cell loss was determined by measuring the cell-free distance between the last visible endothelial cell and the cut edge. Stromal

widening at the edges was defined as "percentage increase of thickness" compared with the thickness of the central cornea $(=100 \%)$.

\section{Materials and methods}

Twenty six human corneas (13 pairs) were taken from the University Eye Bank, Vienna, after 5-14 days of preservation in Optisol. These corneas could not be used for transplantation, either because no blood sample analysis was available or because the donor had a viral infection. Donors were between 56 and 70 years of age (mean 63 years). One of each pair of corneas was used for each technique. Trephinations $(7.5 \mathrm{~mm})$ were performed with either the suction fixated GTS ${ }^{5}$ (using an artificial anterior chamber) or with the PPT (with Pharmacia Superblade trephines). All trephinations were performed by the same surgeon (SK).

For histological investigations corneal buttons were fixed with $2.5 \%$ glutaraldehyde for 2 hours. For LM and TEM, the 22 corneal buttons were first cut into halves. One half of each was used for LM of the entire curvature of the buttons in order to determine the central corneal thickness; the other half was subsequently divided into two quarters by cutting it at right angles to the primary cut edge. Specimens were postfixed in $1 \%$ veronal acetate buffered osmium tetroxide, dehydrated in a series of graded ethanols and

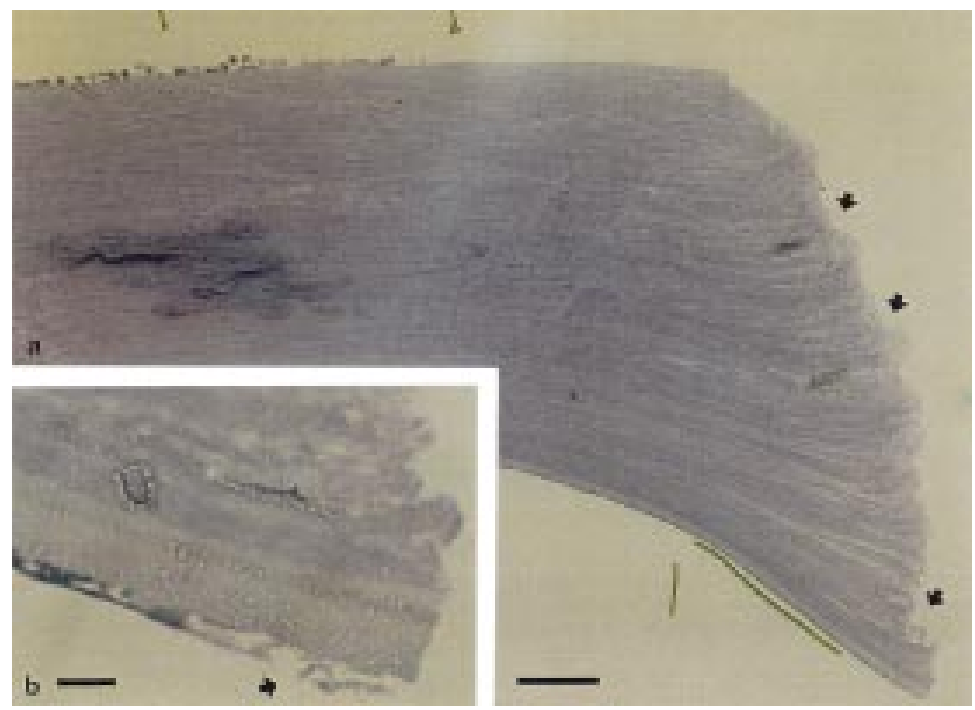

Figure 2 Light microscopy. (a) Cut edges of GTS trephinations show a distinct stromal widening and fibrillar disorder. Note the step-like pattern of the cut edge, which is caused by the forward thrust of the trephine (arrows; $L M \times 100 ;$ bar=150 $\mu \mathrm{m}$ ). (b) Endothelial cells are present up to the cut edge. Only one cell shows signs of degeneration (arrow; LM $\times 1000$; bar=10 $\mu \mathrm{m})$. embedded in Epon 812. For LM, semithin sections were stained with toluidine blue. The ultrathin sections for TEM were stained with tannic acid, uranyl acetate, and lead citrate and examined in a Philips EM 400 microscope.

The extent of the endothelial cell loss and of the stromal widening (Fig 1) at the cut edges of the corneas were measured on the LM sections (three per cornea) of 11 corneas for each technique. Measurements $(\mathrm{n}=33$ per trephine) of endothelial cell loss and corneal widening were performed at both edges of the entire half and one at the edge of a quarter. Endothelial cell loss was determined by measuring the cell-free distance between the last visible endothelial cell and the cut edge (Fig 1). Areas with endothelial cells exhibiting definite signs of cellular degeneration or having lost the contact to their basal lamina were considered to be cell free. Undercutting, mechanical forces, and local stromal swelling led to a widening of the stroma at the edges. This widening (Fig 1) was defined as "percentage increase of thickness" relative to the thickness of the central cornea $(=100 \%)$. For statistical analysis the Mann-Whitney U test was applied for the various groups of samples.

For SEM four corneal donor buttons were dehydrated in a graded series of tertiary butanols, frozen at $-24^{\circ} \mathrm{C}$ and dried in a desiccator by sublimation of the frozen butanol. Finally, the specimens were sputtered with gold and examined in a Cambridge Stereoscan 90 (accelerating voltage $15 \mathrm{kV}$ ).

\section{Results}

FINE STRUCTURE OF THE CUT EDGES

Light microscopy

Both trephines caused stromal widening at the edges. GTS trephination (Fig 2a) produced more stromal widening than did PPT trephination (Fig 3a). The GTS samples showed a step-like pattern (Fig 2a, b) at the edges, which was due to the stepwise forward thrust of this trephine system. In a zone of up to $400 \mu \mathrm{m}$ from the GTS edges the collagen lamellae were disordered and showed undulations (Fig 2a, b). GTS edges were not as smooth as PPT edges and they exhibited considerable fibrillar disorder. In contrast, the cut edges obtained by PPT trephination showed hardly any dislocation of the fibrils (Fig 3a, b).

Transmission electron microscopy

TEM confirmed the LM findings, showing a distinct fibrillar disorder at the GTS edges (Fig 4A) and smooth PPT trephination edges with clearly cut collagen fibrils (Fig 4B).

\section{Scanning electron microscopy}

In SEM the cut edges obtained by the two trephination methods were obviously different. The cut edges of GTS grafts also showed fibrillar disorder at the edges (Fig 5A, B). 

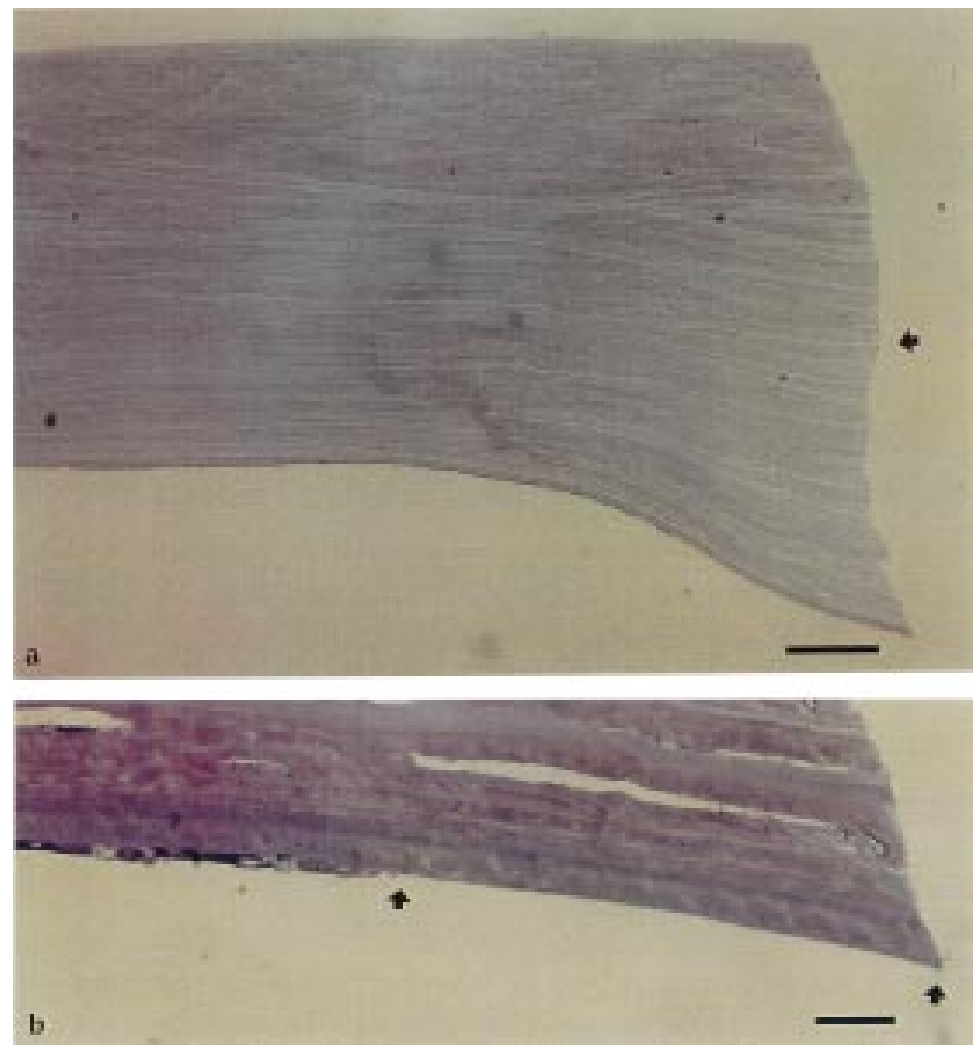

Figure 3 Light microscopy. (a) Stromal widening in the PPT trephinations is lower than in the GTS trephinations (arrow; compare Fig 1), and the cut edges are smooth. Note the minor dislocation of the collagen fibrils $(L M \times 100$; bar $=150 \mu \mathrm{m})$. (b) The Descemet's membrane is denuded from endothelial cells in an area covering about $180 \mu \mathrm{m}$ (arrows; $L M \times 680 ;$ bar $=20 \mu \mathrm{m})$.
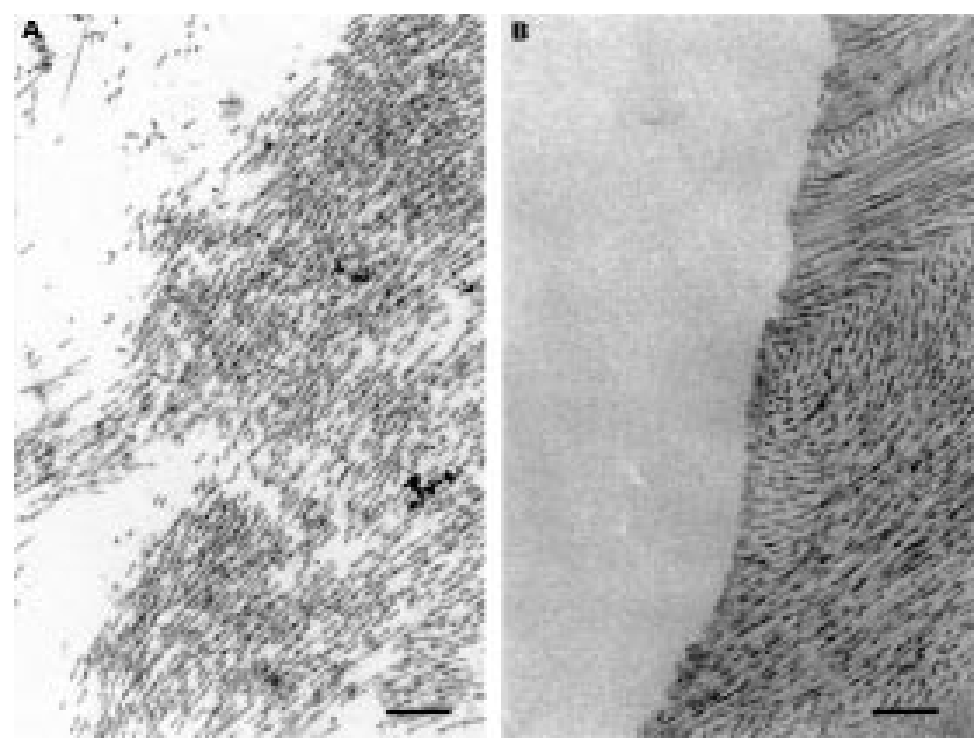

Figure 4 Transmission electron microscopy. (A) GTS trephination. The collagen fibrils at the cut edges show considerable disorder (TEM $\times 9000$; bar=1 $\mu \mathrm{m})$. (B) PPT trephination: The cut edges are smooth, showing hardly any dislocation of collagen fibrils (TEM $\times 9000$; bar $=1 \mu \mathrm{m})$.

However, the dislocated fibrils seemed to compensate for irregularities at the cut surfaces. Clearly cut lamellar endings were visible at the surface of the PPT samples and stromal widening was less extensive in these samples (Fig 6A, B) than in the GTS samples (Fig 5A).
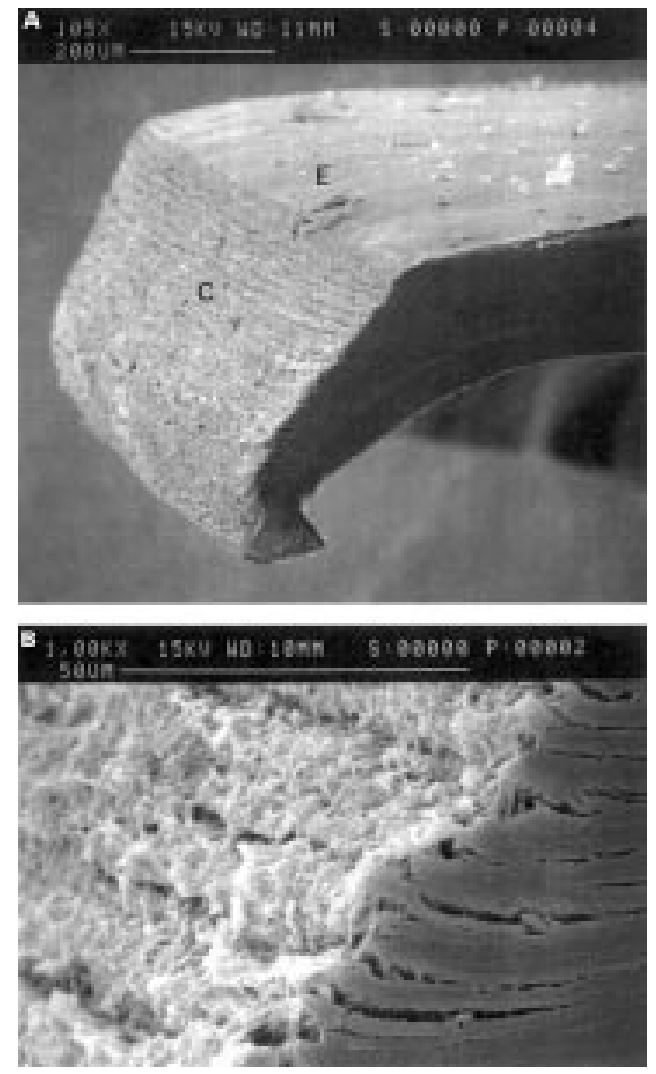

Figure 5 Scanning electron micrographs of cut edges obtained by GTS trephination. (A) Low magnification micrograph showing the shape and stromal widening of a cut edge (C, cut edge; E, epithelial side; $R$, razor cut; SEM $\times 150)(B)$ Higher magnification reveals fibrillar disorder at the cut edge. The dislocated fibrils seem to compensate for irregularities at the surface of the cut $(S E M \times 1100)$.

ENDOTHELIAL CELL DAMAGE

In the light microscope the GTS edges (Fig 2b) showed a much lesser degree of endothelial cell loss than did the PPT edges (Fig 3b). SEM of GTS edges (Fig 7A) also revealed large areas of intact endothelium up to the edges of most buttons. After PPT (Fig 7B) the endothelium also reached up to the edges in a few cases, but most of the cells showed clear signs of cellular degeneration at distances up to approximately $100 \mu \mathrm{m}$ from the cut edes.

QUANTIFICATION OF ENDOTHELIAL CELL LOSS

Endothelial cell loss at the edges was significantly lower with the GTS than with the PPT $(\mathrm{p}<0.001)$. Cell loss extended from 0 to 186 $\mu \mathrm{m}$ from the cut edge (mean 42.2 (50.8) $\mu \mathrm{m}$; $\mathrm{n}=33$ ) for the GTS samples and from 0 to 250 $\mu \mathrm{m}$ (mean 109.3 (68.1) $\mu \mathrm{m} ; \mathrm{n}=33$ ) after PPT. Stromal widening at the edges was significantly smaller $(\mathrm{p}<0.002)$ for the PPT samples $(69 \%$ $(21 \%))$ than for the GTS samples (106\% (24\%)).

\section{Discussion}

In any analysis of corneal tissue damage, the arrangement of the corneal collagen matrix has to be taken into account. Within the stroma collagen fibrils uniform in size and spacing are the major constituents of 

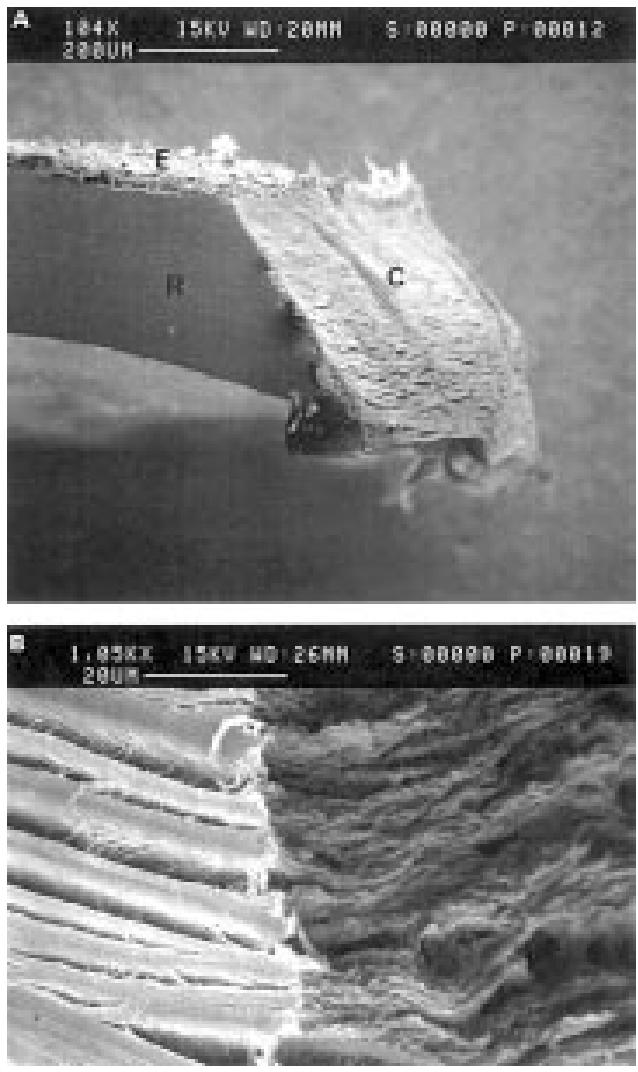

Figure 6 Scanning electron micrographs of cut edges obtained by PPT trephination. (A) Overview showing the shape of a cut edge, which exhibits less stromal widening than that of a GTS edge (C, cut edge; E, epithelial side; $R$, razor cut; $S E M \times 150)$. (B) Higher magnifications show that the collagen lamellae are clearly cut. Corneal lamellar endings can be discriminated at the surface of the cut (arrows; SEM $\times 1100$ ).

band-shaped lamellae. These lamellae are $10-230 \mu \mathrm{m}$ wide and $0.2-2.5 \mu \mathrm{m}$ thick. They cross one another at varying angles and split into branches and sub-branches, which are interlaced and merge with adjacent ones. $^{20-24}$

Astigmatism is a significant problem after penetrating keratoplasty. ${ }^{13-8}$ Despite of advances in mechanical trephine design and suture technique, the mean postoperative astigmatism has been reported to be between 2.5 and 5 dioptres in a large keratoplasty series. ${ }^{13-6}$ Postoperative astigmatism is thought to be a result of imprecise trephination and differences between the donor button and the recipient cornea. ${ }^{1378}$

When the GTS is used, the average postoperative astigmatism is very low $(2.55 \mathrm{D}$; range $0-4.0 \mathrm{D}$ ) after PKP for keratoconus. ${ }^{5}$ The advantage of the GTS is that both the donor buttons and their recipient beds are produced by the same suction fixated system, thus providing transplants and recipient beds with the same size and shape. In contrast, astigmatism is higher when the GTS (for the recipient bed) is combined with another trephination technique for the donor button. ${ }^{5}$ In agreement with that, Perlman ${ }^{1}$ suggested that a main reason for postoperative astigmatism is a significant discrepancy between an
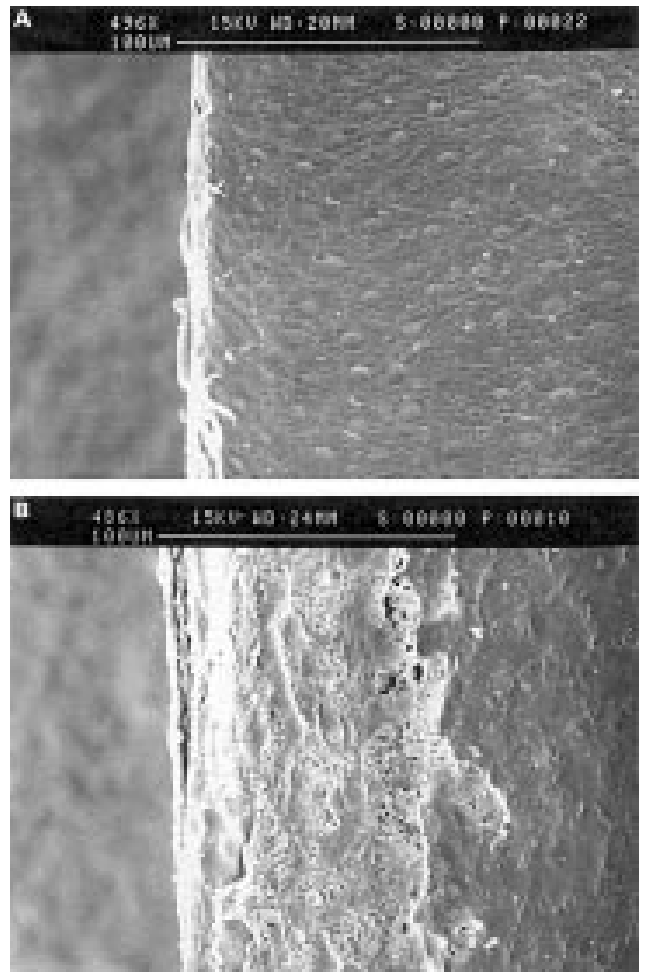

Figure 7 Scanning electron microscopy. (A) GTS trephination. The endothelium is intact up to the edges $(S E M \times 500)$. (B) PPT trephination. The intact endothelium sometimes also reaches to the edges. However, most of the cells show clear signs of cellular degeneration $u p$ to $100 \mu \mathrm{m}$ from the cutting edges $(S E M \times 500)$.

oval recipient hole and a round donor button. A further reason for postoperative astigmatism is the morphological differences at the cut edges when two different trephination techniques are used in the same procedure. The GTS produced considerably more stromal widening and more undercutting at the cut edges than did the PPT. These effects were mainly the result of the forward thrust of the GTS and could therefore also be found at the edges of the remaining corneoscleral rim (data not shown). Our study has shown that the various trephination techniques produce distinct morphological differences at the cut edges of the donor buttons and their recipient beds. These differences can produce instability of the transplants in their recipient beds and lead to difficulties in securing them tightly and neutrally. A trephination system that can be used for the preparation of both the donor button and the recipient bed, such as the GTS, seems to be advantageous. In addition, it is well known that corneal scars after PKP are a source of weakness, even when adequate healing occurs. ${ }^{9} 10$ The disordered collagen fibrils at the edges of a GTS transplant can intermingle with fibrils of the recipient GTS bed when the transplant is secured with sutures. In our opinion this situation improves the stability and the biomechanical properties of the scar. However, it has to be emphasised that storage and trephination of the donor buttons cause various degrees of corneal swelling, which can lead in more severe cases to clinically significant 
suture problems. GTS trephination causes more stromal swelling and lamellar distortion at the cut edges than does PPT and is associated with a higher risk of severe corneal swelling, which can transfer the positive effect on transplant stability-produced by intermingling fibrils - into the disadvantage of postoperative astigmatism that results from insecure suturing of the transplant. In addition, because of the varying amounts of stromal swelling resulting from storage and trephination, we have calculated the corneal widening at the edges in terms of percentage increase in thickness relative to the central corneal thickness. We believe that this is a reliable measure of corneal widening produced by the trephination procedures at the cutting edges.

Another very important factor for the success of the penetrating keratoplasty procedure is the degree to which intact endothelial cells are preserved after PKP, since they are essential for corneal transparency and nutrition. ${ }^{11}$ Prospective and retrospective studies have reported a $21 \%$ decrease per year in endothelial cells in the centre of the button during the first 3 years after PKP, which then stabilised to $0.5 \%$ per year. ${ }^{12-14}$ The overall result was a mean cell loss of $73 \%$ after 10 years. ${ }^{15}$ However, the greatest degree of endothelial cell loss occurs intraoperatively (real loss) at the edges of the peripheral graft and in the recipient cornea near the wound. ${ }^{15-18}$ After trephination with the Hessburg-Barron trephine, Legeais et al ${ }^{17}$ found a $150 \mu \mathrm{m}$ wide, annular zone of endothelial damage in the recipient cornea that was located $1.2 \mathrm{~mm}$ away from the cut edge. Sanchez-Thorin et $a l^{16}$ reported an endothelial cell loss of about $150 \mu \mathrm{m}$ from the edge with the Tampa trephine and about 50 $\mu \mathrm{m}$ with the Weck trephination technique in experiments using cat corneas. After excimer laser trephination, Serdarevic et $a l^{2}$ found an annular endothelial cell loss at the edges of one and five cell diameters and a cell loss of up to 10 cell diameters with the Hanna trephine and the Franceschetti trephine. Our results are basically in agreement with these studies in showing less endothelial cell loss with a controlled system, compared with a free hand punch. The endothelial cell loss caused by PPT trephination, at 109.3 (68.1) $\mu \mathrm{m}$ was well within the range of other free hand trephines. The difference in endothelial cell loss that we observed between the two techniques might have been due to reduced mechanical control with the free hand trephine. However, clinical follow up studies are required to determine whether this difference in endothelial cell loss is of clinical relevance to transplant survival.

To investigate the endothelial damage in an upright projection, vital staining and SEM $^{216} 17$ provides a good overview of the extent of the damaged zone. However, as we have shown in the present study, trephination produces stromal widening at the cut edges; this effect was seen for both techniques. Thus, the radius of corneal curvature decreased considerably near the edge, and two dimensional measurements of the area of endothelial cell loss might lead to an underestimation of the extent of the cell loss. We therefore decided to measure the distance over which the endothelial cell loss extended as well as the amount of stromal widening on light microscopic cross sections which were cut perpendicular to the cut edges of the corneal buttons. In our opinion this approach considerably improved the validity of the measurements.

On the basis of our observations, we conclude that the non-fixated punching hand trephine produces significantly more endothelial cell loss at the cut edges than does the GTS trephination technique. The extent of fibrillar dislocation as well as the degree of stromal widening at the cut edge was higher with the GTS. It should be emphasised, however, that both trephination systems are well developed and produced only minor tissue damage to the corneal grafts.

The authors wish to thank Ms E Scherzer for her technical assistance and Ms R Amon for organising the study and providing the technical equipment.

ing the technical equipment.
This study has been presented in part at ARVO 1997, Ft This study has been

The authors state that they did not receive funding and do not have any financial interest in the products mentioned in the have any.
study.

1 Perlman E. An analysis and interpretation of refractive errors after penetrating keratoplasty. Ophthalmology $1981 ; 88: 39-45$

2 Serdarevic O, Hanna K, Gribomont A, et al. Excimer laser trephination in penetrating keratoplasty. Morphologic features and wound healing. Ophthalmology 1988;95:493505.

3 Heidemann D, Sugar A, Meyer R, et al. Oversized donor grafts in penetrating keratoplasty. Arch Ophthalmol 1985; 103:1807-11

4 Wiffen S, Maguire L, Bourne W. Keratometric results of penetrating keratoplasty with the Hessburg-Baron and Hanna trephine systems using a standard double-running suture technique. Cornea 1997;16:306-13.

5 Bekmont S, Zimm J, Storch R, et al. Astigmatism after penetrating keratoplasty using the Krumreich guided trephine etrating keratoplasty using the Krumreich
system. Refract Corneal Surg 1993;9:250-4.

6 Binder P. Selective suture removal can reduce postkeratoplasty astigmatism. Ophthalmology 1985;92:1412-16.

plasty astigmatism. Ophthalmology 1985;92:1412-16.
Foulks G, Perry H, Dohlman C. Oversize corneal donor grafts in penetrating keratoplasty. Ophthalmology 1979;86: 490-6.

8 Bourne W, Davison J, O'Fallon W. The effects of oversize donor buttons on postoperative intraocular pressure and corneal curvature in aphakic penetrating keratoplasty. Ophthalmology 1982;89:242-6.

9 Simonsen A, Andreasen T, Bendix K. The healing strengh of the corneal wound in the human eye. Exp Eye Res 1982; 35:287-92.

10 Friedman A. Late traumatic wound rupture following successful partial penetrating keratoplasty. Am f Ophthalmol 1973;75:117-20.

11 Bourne W, Kaufman H. The endothelium of clear corneal transplants. Arch Ophthalmol 1976;94:1730-2.

12 Bourne W. Morphologic and functional evaluation of the endothelium of transplanted human corneas. Trans $\mathrm{Am}$ Ophthalmol Soc 1983;81:403-50.

13 Bourne W, Kaufman H. Specular microscopy of human corneal endothelium in vivo. Am $\mathcal{F}$ Ophthalmol 1976;81: $319-23$

14 Olsen T. The specular microscopic appearance of corneal graft endothelium during an acute rejection period. Acta Ophthalmol 1979;57:882-90.

15 Abbott R, Fine M, Guillet E. Long term changes in corneal endothelium following penetrating keratoplasty: specular microscopic study. Ophthalmology 1983;90:676-85.

16 Sanchez-Thorin J, Rocha G, Bowyer B, et al. The Tampa rephine technique with cat corneal endothelium. Cornea 1997;16:79-87.

17 Legeais J, Parel J, Simon G, et al. Endothelial damage by the corneal Hessburg-Barron vacuum trephine. Refract Corneal Surg 1993:9:255-8.

18 Schwarz A, Bourne W. Endothelial cell loss after keratoplasty. In: Brightbill F, ed. Corneal surgery. 2nd ed. St Louis: Mosby, 1993:300-5. 
19 Tanne E. Corneal trephines and cutting blocks. In: Brightbill F, ed. Corneal surgery. 2nd ed. St Louis: Mosby, 1993:193-8.

20 Komai Y, Ushiki T. The three-dimensional organization of collagen fibrils in the human cornea and sclera. Invest $O p h-$ thalmol Vis Sci 1991;32:2244-58.

21 Radner W, Zehetmayer M, Aufreiter R, et al. Interlacing and cross angle distribution of collagen lamellae in the human cornea. Cornea 1998;17:537-43.
22 Radner W, Zehetmayer M, Skorpik Ch, et al. Altered arrangement of collagen lamellae in keratoconus corneas. 23 Radner W, Zehenayer 1 ,

Radner W, Zehetmayer M, Mallinger R, et al. Zur dreidimensionalen Anordnung der kollagenen Lamellen im posterioren Stroma der menschlichen Hornhaut. Spektrum der Augenheilkunde 1993;7:77-80.

24 Polack F. Morphology of the cornea. Am $\mathcal{f}$ Ophthalmol 1960;51:1051-6. 